\title{
Rumpi dan Gosip Dalam Pandangan Islam
}

\author{
Siti Magfiroh \\ Ushuluddin dan Adab \\ Universitas Islam Negeri Maulana Hasanuddin Banten \\ E-mail: sitimagfiroh512@gmail.com
}

\begin{abstract}
Abstrac
This paper will provide a description of the act of gibah or gossip. This is important because in this day and age, talking about badness among humans has become a common sight. Ghibah wherever and whenever is a despicable morality that we as Muslims should not make a culture in the community or family. Various consequences of ghibah, both from our own environment (social environment), or even within ourselves emotionally. In the hadith, the hadith narrated by Muslim number 2589 is described which is considered multiple interpretations because it prohibits gibah. the importance of safeguarding the tongue from the dangers of talking about other people whether he knows it or not. In the infotainment, for example, the culture of discussing the disgrace of other people seems to have become commonplace and has a lot of interest, but the question here is for example news or discussing whether marriage is also a joke, and sometimes at the request of the artist's own fame. More than that, trying to explain the understanding and arguments of al-qur'an and hadith about ghibah, law. The purpose of this research is to find out the hadiths about backbiting and and the position of ghibah. In connection with the above, questions arise, namely: first, to find out the meaning of ghibah and according to the hadiths and second, to find out the position of ghibah and according to the hadith which includes age, law, tips to overcome in order to avoid backbiting. This research was conducted using a book survey method. With the following steps: collect the existing hadiths and reveal the asbab al-wurud if they are contained in the hadith, analyze the hadiths, reveal the verses of the Qur'an as reinforcement, and finally draw conclusions.
\end{abstract}

Keyword: Gossip and Gossip in the Qur'an surah Al-Hujurat: 12

\section{Abstrak}


Tulisan ini akan memberikan penjabaran perbuatan gibah atau gosip. Ini menjadi penting karena di masa kini, membicarakan keburukan sesama manusia sudah menjadi pemandangan yang biasa. Ghibah dimanapun dan kapanpun merupakan akhlak tercela yang tidak patut kita sebagai muslim menjadikan budaya dilingkungan masyarakat ataupun keluarga. Berbagai akibat dari bahya ghibah, baik iut dari lingkungan sendiri (lingkungan social), atau pun dalam diri kita sendiri secara emosi. Dalam hadist dipapparkan hadis riwayat Muslim nomor 2589 yang dianggap multi tafsir karena mengandung pelarangan gibah. pentingnya menjaga lidah dari bahaya membicarakan orang lain baik sepengetahuannya atau pun tidak diketahui olehnya. Dalam infotaiment misalnya, budaya membincangkan aib orang lain seakan-akan telah menjadi biasa dan memilki banyak peminat, namun yang menjadi pertanyaan disini contohnya berita atau membicarakan pernikahan apakah juga termasuk ghibah, dan terkadang atas permintaan sendiri untuk ketenaran sang artis. Lebih dari itu, mencoba memaparkan pengertian serta dalil al-qur'an dan hadits tentang ghibah, hokum Adapun tujuan penelitian ini didalamnya adalah untuk mengetahui hadits- hadits tentang ghibah dan dan kedudukan ghibah Berkaitan dengan hal tersebut di atas, maka timbulah pertanyaan yaitu: pertama, untuk mengetahui makna ghibah dan menurut hadits dan kedua, untuk mengetahui kedudukan ghibah dan menurut hadits yang meliputi baya, hukum, kiat mengatasi agar terhindar dari ghibah Penelitian ini dilakukan dengan menggunakan metode studi pustaka (book survey). Dengan langkah-langkah sebagai berikut : menghimpun hadits-hadits yang ada serta mengungkapkan menganalisa hadits, mengungkapakan ayat Al-Qur'an sebagai penguat, dan akhirnya mengambil kesimpulan

Kata kunci: Rumpi dan Gosip dalam Qur'an surat Al-Hujurat: 12

\section{Pendahuluan}

Salah satu bentuk kemaksiatan yang banyak dilakukan oleh manusia adalah gemar membicarakan orang lain atau yang diistilahkan dengan gosip, dalam islam disebut dengan ghibah. Padahal dalil-dalil yang menerangkan tentang haramnya ghibah sangatlah tegas dan jelas dalam Al Qur’an. Gosip (dalam bahasa Arab yaitu ghibah الغيبة Ghibah adalah menceritakan seseorang dengan sesuatu yang tidak disukainya sehingga ia merupakan sifat yang tercela dan dilarang oleh agama berdasarkan al-Qur'an dan Hadis Nabi karena mengandung bahaya besar, baik individu maupun masyarakat. Di antara dampak negatif ghibah pada individu adalah melukai hati seseorang sehingga dapat menimbulkan permusuhan. Sementara dampak negatifnya 
untuk masyarakat adalah mengacaukan hubungan kekeluargaan, persaudaraan dan kemasyarakatan serta menimbulkan saling curiga-mencurigai.

Imam Ibnul Qayyim berkata, Akhlak yang tercela adalah bermula dari kesombongan dan rendah diri.Dari kesombongan muncul sikap bangga, sok tinggi, hebat, ujub, hasad, keras kepala, zhalim, gila pangkat, kedudukan dan jabatan, senang dipuji padahal tidak berbuat sesuatu dan sebagainya.Ibnul Qayyim juga mengatakan bahwa sebagaimana akhlak terpuji, akhlak tercela juga memiliki akar di mana satuan-satuannya dapat dikelompokkan. Jika akar perilaku manusia ada dalam pikiran dan jiwanya, maka akar penyakit akhlak juga akan selalu ada disana. Salah satu akhlak tercela (mazmumah) yang merupakan penyakit hati yaitu ghibah dan fitnah.

\section{Pembahasan}

Pengertian Rumpi atau gosip (Gibah)

Al-Gibah secara bahasa merupakan "min al ightiyab" diartikan sebagai yang tidak tampak. ${ }^{1}$ Gibah juga dapat berarti umpatan, fitnah dan gunjingan. Gibah dalam bahasa Indonesia berarti perkataan yang memburuk-burukkan orang lain.

Gibah dapat pula diartikan penggunjingan yang diidentikan dengan kata gosip, yaitu cerita negatif tentang seseorang. Dengan demikian, gibah dapat dipahami mempunyai arti kurang lebih sama dengan kata umpatan, penggunjingan dan gosip. ${ }^{2}$

Kamus Besar Bahasa Indonesia mendefiniskan gibah adalah obrolan tentang orang-orang lain atau cerita-cerita negatif tentang seseorang. ${ }^{3}$ juga sering diidentikkan dengan istilah. rumor dan isu yang merupakan suatu berita yang menyebar tanpa berlandaskan pada fakta yang belum atau tidak melalui sebuah klarifikasi (tabayyun). Maka, gosip merupakan sesuatu yang masih abu-abu karena bisa saja benar, namun bisa pula salah. Gosip, isu, dan rumor, ketiganya memiliki pengertian yang identik yakni informasi yang mengandung dua kemungkinan antara

\footnotetext{
${ }^{1}$ Ahmad Warson Munawir, Al-Munawir: Kamus Arab-Indonesia (Jakarta: Pustaka Progresif, 1984), hal. 1025

${ }^{2}$ WJS Poerwadarminta, Kamus Umum Bahasa Indonesia (Jakarta: (Jakarta: PN. Balai Pustaka, 1985), hal. 1125

${ }^{3}$ Badudu and Sutan Mohammad Zain, Kamus Umum Bahasa Indonesia (Jakarta: Pustaka Sinar Harapan, 1994), hal. 469.
} 
benar dan salah, atau dengan kata lain adalah asal-usulnya tidak jelas dan diragukan kebenarannya.

Gosip tidak bisa disamakan dengan berita karena berita adalah informasi yang sudah diyakini kebenarannya melaui fakta, data, ataupun konfirmasi langsung dari para pihak (narasumber). Namun, fakta juga harus diverifikasi dulu, dipastikan kebenarannya dengan dilakukan cek-ricek atau konfirmasi.Dalam bahasa agama (Islam), verifikasi atau konfirmasi dikenal dengan istilah tabayyun. Jika tidak dilakukan sebuah tindakan verifikasi, maka sebuah berita hanya akan menjadi gosip.

Gosip dalam bahasa Arab disebut sebagai gibah. Mengenai hal ini, nabi menjelaskan definisi gibah dalam sebuah hadis riwayat Muslim sebagaimana disebutkan sebelumnya. Dari hadis tersebut, dapat ditarik kesimpulan bahwa gosip dalam perspektif penjelasan nabi adalah menceritakan tentang keburukan seseorang pada orang lain yang benar-benar ada (sesuai kenyataan) pada orang tersebut. Sedangkan menceritakan tentang keburukan seseorang yang tidak sesuai merupakan sebuah kebohongan.Sebuah sensasi berupa kebohongan ataupun gimmick, saat ini menjadi suatu tontonan yang menarik bagi masyarakat. Hal ini terlihat dari maraknya tayangan gosip dan berbagai reality show yang lebih condong kepada cerita-cerita buruk terhadap seseorang. ${ }^{4}$

Terkait bahanya permusuhan antar sesama manusia, nabi Muhammad menjelaskan bahwa lidah manusia merupakan salah satu sumber utama munculnya dusta, buruk sangka, adu domba, bertengkar, bermusuhan, mengutuk, bersenda-gurau yang berlebihan, menghina, berdebat kusir,serta gibah (menggunjing). Gibah dapat melukai hati seseorang, menimbulkan permusuhan, mengacaukan hubungan kemasyarakatan, dan memunculkan rasa saling curiga. Berbagai potensi dampak ini kemudian mendorong Majelis Ulama Indonesia mengeluarkan fatwa terkait gosip atau gibah di media sosial. ${ }^{5}$

Adanya fatwa dari lembaga Majelis Ulama Indonesia tidak lantas menghentikan perilaku masyarakat dalam bergosip baik melalui media sosial maupun secara langsung. Membicarakan keburukan sesama manusia seolah telah menjadi sebuah kewajaran di masa kini dengan adanya

\footnotetext{
${ }^{4}$ Ilyas, Ghibah Perspektif Sunnah, hal. 157.

${ }^{5}$ Fatwa Majelis Ulama Indonesia Nomor 24 Tahun 2017, Komisi Fatwa Majelis Ulama Indonesia, hal. 1-20. 
tayangan-tayangan yang menyajikan acara gosip. Gosip tentang public figure seperti artis, tokoh politik, dan sebagainya selalu mengundang antusias publik untuk terus mengikuti perkembangannya. Antusias masyarakat dalam mengikuti perkembangan gosip menjadikan para produser TV terus menyajikan tayangan-tayangan berbau gosipt anpa disertai edukasi yang cukup. ${ }^{6}$

Ghibah secara syari yaitu menceritakan tentang seseorang yang tidak berada di tempat dengan sesuatu yang tidak disukainya. Baik menyebutkan aib badannya, keturunannya, akhlaknya, perbuatannya, urusan agamanya, dan urusan duanianya. Sebagaimana dalam Hadis dijelaskan pengertian ghibah sebagaimana penjelasan Hadis yang diriwayatkan oleh Abu Hurairah:

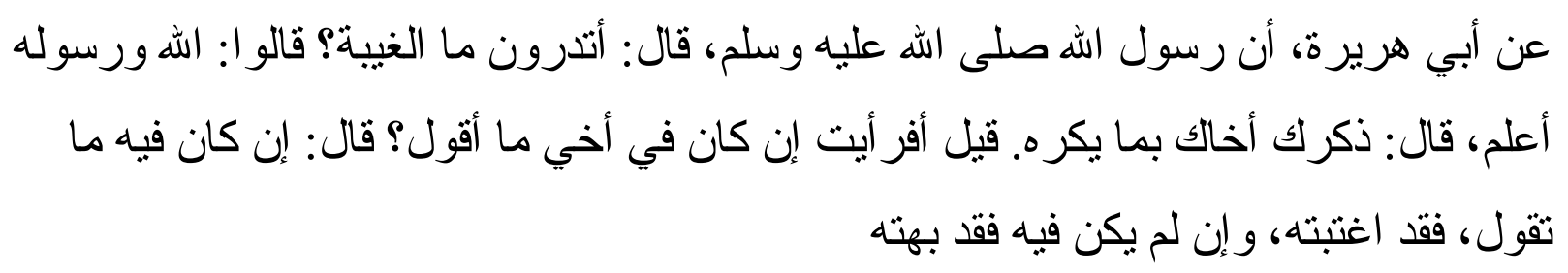

Artinya:

Tahukah kalian apa itu ghibah (menggunjing)? Para sahabat menjawab : Allah dan Rasul-Nya yang lebih tahu. Kemudian beliau bersabda: Ghibah adalah engkau membicarakan tentang saudaramu sesuatu yang dia benci. Ada yang bertanya. Wahai Rasulullah bagaimana kalau yang kami katakana itu betul-betul ada pada dirinya?. Beliau menjawab : Jika yang kalian katakan itu betul, berarti kalian telah berbuat ghibah. Dan jika apa yang kalian katakan tidak betul, berarti kalian telah memfitnah (mengucapkan suatu kedustaan) ${ }^{7}$

Berdasarkan Hadis di atas, ghibah diartikan menyatakan tentang sesuatu yang terdapat pada diri seseorang muslim di saat ia tidak berada di tempat, dan apa yang disebutkan memang ada pada orang tersebut tetapi ia tidak suka hal tersebut dinyatakan. Adapun jika yang disebutkan tidak ada padanya, berarti telah memfitnahnya. Dalam Hadis di atas sudah sangat jelas mengenai ghibah. Setelah mepelajari dan memahami Hadis di atas, dapat disimpulkan bahwa ghibah yaitu

${ }^{6}$ Muhammad Munzir, Gosip Dalam Pandangan Hadis: Suatu Kajian Tematik (Fakultas Ushuluddin UIN Alauddin, 2011), hal. 25.

${ }^{7}$ Muslim, Shahih Muslim (Beirut: Dar-al Kitab Araby, 2004), hal. 128. 
menyebutkan sesuatu yang sebenarnya tentang seseorang, baik tentang agamanya, akhlaknya, ataupun tentang yang lainnya, di saat orang tersebut tidak hadir atau tidak mendengarnya secara lansung, dan jika ia mengetahui tidak menyukainya.

Yusuf Al Qardhawi mendefinisikan makna ghibah sebagaimana dijelaskan dalam kitab Al Halal Wa al Haram Fi al Islam

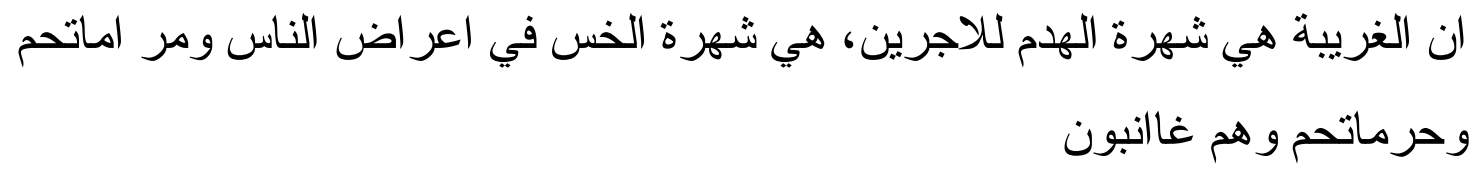

Artinya:

"Ghibah adalah suatu keinginan untuk menghancurkan orang, suatu keinginan untuk menodai harga diri, kemuliaan dan kehormatan orang lain, sedang mereka itu tidak ada di hadapannya". 8

Menurut mayoritas ulama Hadis kata كي بَّ adalah kekurangan seseorang baik yang terkait dengan fisik, agama, dunia, jiwa, akhlak, harta, anak, orang tua, istri pembantu, pakaian, cara jalan dan lain-lain yang semuanya mengarah pada kekurangan dan perendahan. Baik menyebutkan aib badannya, keturunannya, akhlaknya, perbuatannya, urusan agamanya, ataupun urusan dunianya.

Ghibah dapat dilakukan dengan lisan, dan tulisan. Seperti halnya ghibah yang sering dilakukan oleh masyarakat di Kecamatan Pulau Rakyat, ghibah dilakukan dengan perbuatan saling berkomentar di jejaring media sosial facebook, karena biasanya jika sudah asik berbalas komentar dengan teman maka akan bercerita tanpa disadari aib keluarga dan orang lain diikutkan menjadi bahan untuk dibicarakan.

pengertian ghibah, sebagaimana penjelasan Hadis yang diriwayatkan oleh Abu Hurairah

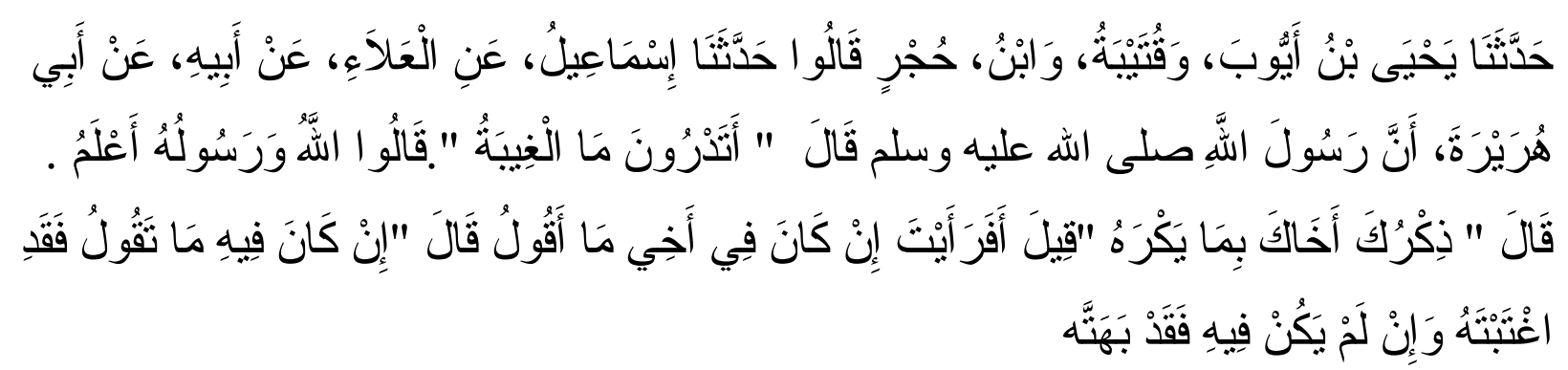

${ }^{8}$ Yusuf Al Qardhawi, Al Halal Wa al Haram Fi al Islam (Kairo: Maktabah Wahbah, 1993), hal.305 
Artinya: "Tahukah kalian apa itu ghibah (menggunjing)?. Para sahabat menjawab : Allah dan Rasul-Nya yang lebih tahu. Kemudian beliau bersabda : Ghibah adalah engkau membicarakan tentang saudaramu sesuatu yang dia benci. Ada yang bertanya. Wahai Rasulullah bagaimana kalau yang kami katakana itu betul-betul ada pada dirinya?. Beliau menjawab : Jika yang kalian katakan itu betul, berarti kalian telah berbuat ghibah. Dan jika apa yang kalian katakan tidak betul, berarti kalian telah memfitnah (mengucapkan suatu kedustaan)".9

\section{Pandangan Al-Qur’an dan Hadits Rasulullah tentang Rumpi dan ghosip}

Al- Qur"an dan Hadis telah memperingatkan tentang ghibah dan melarang perbuatan tersebut. Berdasarkan firman Allah Swt dalam Surah Al Hujurat: 12

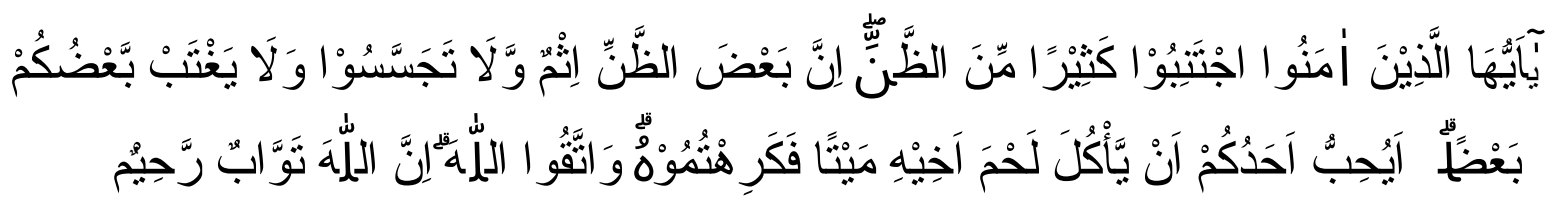

Artinya:

Wahai orang-orang yang beriman! Jauhilah banyak dari prasangka, sesungguhnya sebagian prasangka itu dosa, dan janganlah kamu mencari-cari kesalahan orang lain, dan janganlah ada di antara kamu yang menggunjing sebagian yang lain. Apakah ada di antara kamu yang suka memakan daging saudaranya yang sudah mati? Tentu kamu merasa jijik. Dan bertakwalah kepada Allah, sungguh Allah Maha Penerima Tobat, Maha Penyayang. ${ }^{10}$ (QS Al-Hujurat:12)

Hai orang-orang yang beriman, jauhilah kebanyakan dari prasangka, sesungguhnya sebagian prasangka itu adalah dosa) artinya, menjerumuskan kepada dosa, jenis prasangka itu cukup banyak, antara lain ialah berburuk sangka kepada orang mukmin yang selalu berbuat baik. Orang-orang mukmin yang selalu berbuat baik itu cukup banyak, berbeda keadaannya dengan orang-orang fasik dari kalangan kaum muslimin, maka tiada dosa bila kita berburuk sangka terhadapnya menyangkut masalah keburukan yang tampak dari mereka.

${ }^{9}$ Muslim, Shahih Muslim (Beirut: Dar-al Kitab „Araby, 2004), hal. 128.

${ }^{10}$ Dapatermen Agama RI, Al Qur’an dan Terjemahnya (Surabaya: Karya Agung, 2006) 
و وَلَا تَجَسَّسُو أ (dan janganlah kalian mencari-cari kesalahan orang lain) lafal Tajassasuu pada asalnya adalah Tatajassasuu, lalu salah satu dari kedua huruf Ta dibuang sehingga jadilah Tajassasuu, artinya janganlah kalian mencari-cari aurat dan keaiban mereka dengan cara menyelidikinya.

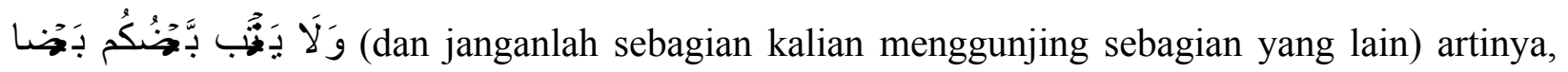
janganlah kamu mempergunjingkan dia dengan sesuatu yang tidak diakuinya, sekalipun hal itu benar ada padanya.

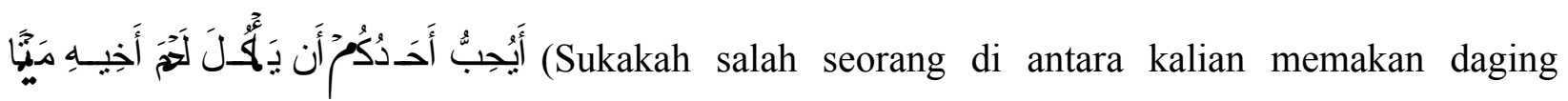
saudaranya yang sudah mati?) lafal Maytan dapat pula dibaca Mayyitan; maksudnya tentu saja hal ini tidak layak kalian lakukan.

فَكَرِ هُهُهُوْهُ (Maka tentulah kalian merasa jijik kepadanya) maksudnya, mempergunjingkan orang semasa hidupnya sama saja artinya dengan memakan dagingnya sesudah ia mati. Kalian jelas

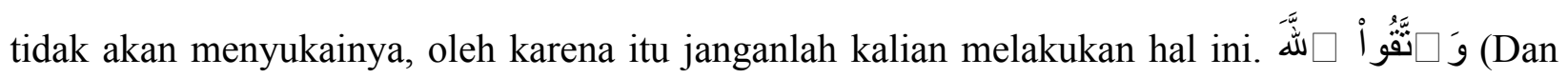
bertakwalah kepada Allah) yakni takutlah akan azab-Nya bila kalian hendak mempergunjingkan

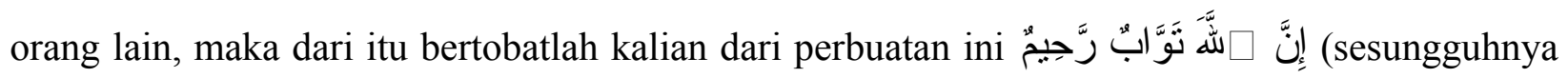
Allah Maha Penerima tobat) yakni selalu menerima tobat orang-orang yang bertobat (lagi Maha Penyayang) kepada mereka yang bertobat. ${ }^{11}$

Hadis yang diriwayatkan oleh Ibnu Mas"eud menjelaskan tentang keharaman ghibah

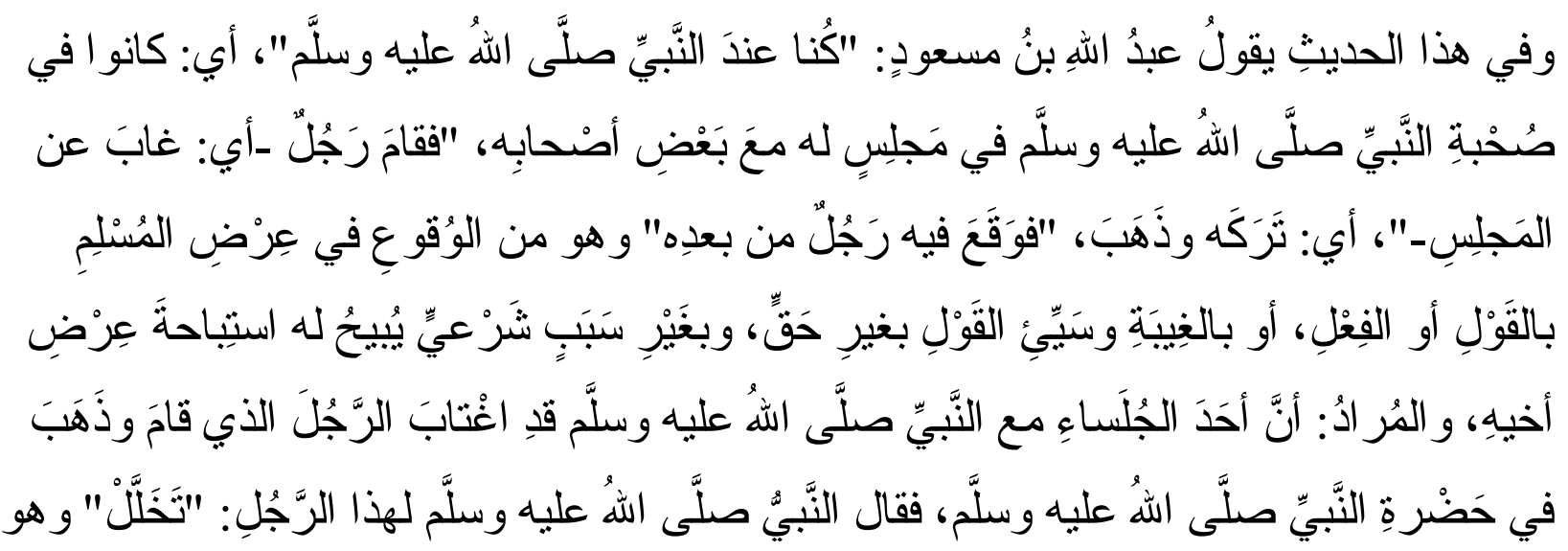

${ }^{11}$ Jalaluddin Al-Mahalli, Tafsir Jalalain (Bandung: Sinar Baru 1990), hal. 186 


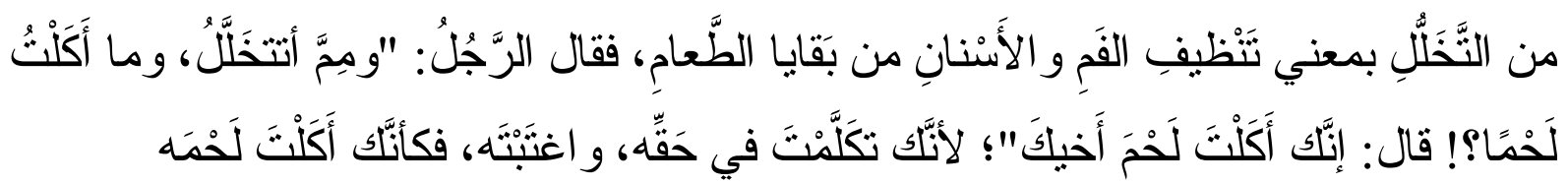

Artinya:

"Ibnu Mas'ud pernah berkata : kami pernah berada di tempat Nabi Saw., tiba-tiba ada seorang laki-laki berdiri meninggalkan majelis, tiba-tiba ada laki-laki lain mengumpatnya sesudah ia tidak ada, maka kata Nabi kepada laki-laki ini : Berselilitlah kamu! Orang tersebut bertanya: Mengapa saya harus berselilit sedang saya tidak makan daging? Maka kata Nabi: Sesungguhnya engkau telah makan daging saudaramu."

Manusia sebagai makhluk sosial, di saat berinteraksi terkadang disadari atau tanpa disadari ketika berkumpul perkataan yang diucapkan adalah penyakit lisan, yang dapat dikategorikan ghibah. ${ }^{12}$

Mengeluarkan kata-kata yang bagaimanapun dari lisan sungguh teramat mudahnya. Akan tetapi, apa dampaknya dan baimana akibatnya, itulah yang sering tidak terpikirkan sepatah kata yang telah terucap sama sekali tidak akan membuat tubuh seseorang terluka, namun siapa yang tahu kalau justru hatinya yang tersayat-sayat. Atau sebaliknya, sepatah kata yang terucap, justru menjadi penyebab si pengucapnya mendapat celaka ataupun selamat, baik ketika di duni maupun di akhirat kelak.

Dalam kitab Hadis Arbain Nawawiyah dituliskan bahwa ucapan ada tiga bagian: kebaiakan yaitu tuntutan, keburukan yaitu yang diharamkan, dan laghum yaitu ucapan yang tidak berisikan kebaikan maupun keburukan. ${ }^{13}$ Perkataan yang diucapkan tidak keluar dari empat hal berikut ini $^{14}$ :

1. Ucapan yang seluruhnya mengandung mudharat

2. Ucapan yang seluruhnya mengandung manfaat

${ }^{12}$ Maulana Muhammad Yusuf, Muntakhab Ahadis, Dalil-Dalil Enam Sifat Utama (Yogyakarta: Ash Shaff, 2007), hal. 672 .

${ }^{13}$ Muhammad bin Shalih al utsaimin, Hadis Arba 'in Nawawiyah (Yogyakarta: Absolut, 2005), hal. 294

${ }^{14}$ Abdullah bin Jarullah, Awas Bahaya Lidah (Jakarta: Gema Isnani Press, 1993), hal. 8. 
3. Ucapan yang seluruhnya mengandung manfaat dan mudharat

4. Ucapan yang tidak mengandung mengandung manfaat dan mudharat. ${ }^{15}$

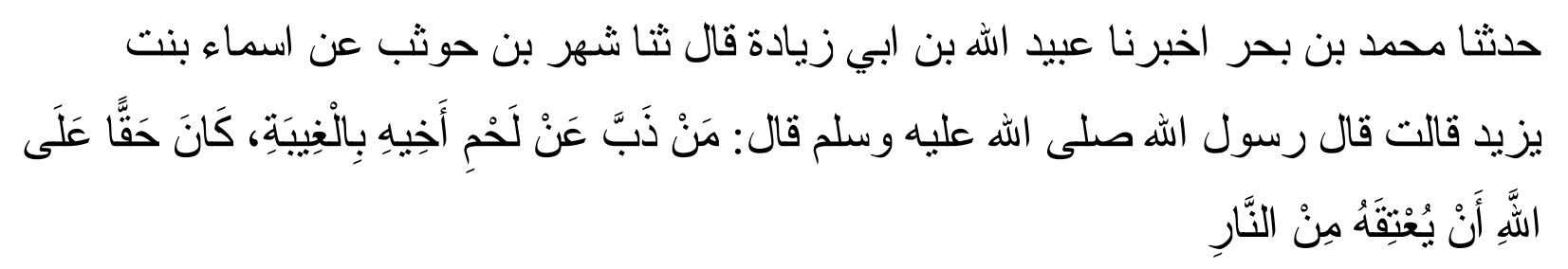

Artinya:

Telah menceritakan kepada kami Muhammad bin Bakr telah mengabarkan kepada kami Ubaidullah bin Abu Ziyad dari Syahr bin Hausyab dari Asma" binti Yazid dia berkata, "Rasulullah SAW bersabda: "Barangsiapa menahan diri dari memakan daging saudaranya dalam Gibah , maka menjadi kewajiban Allah untuk membebaskannya dari api neraka." (HR. Ahmad 26.328)

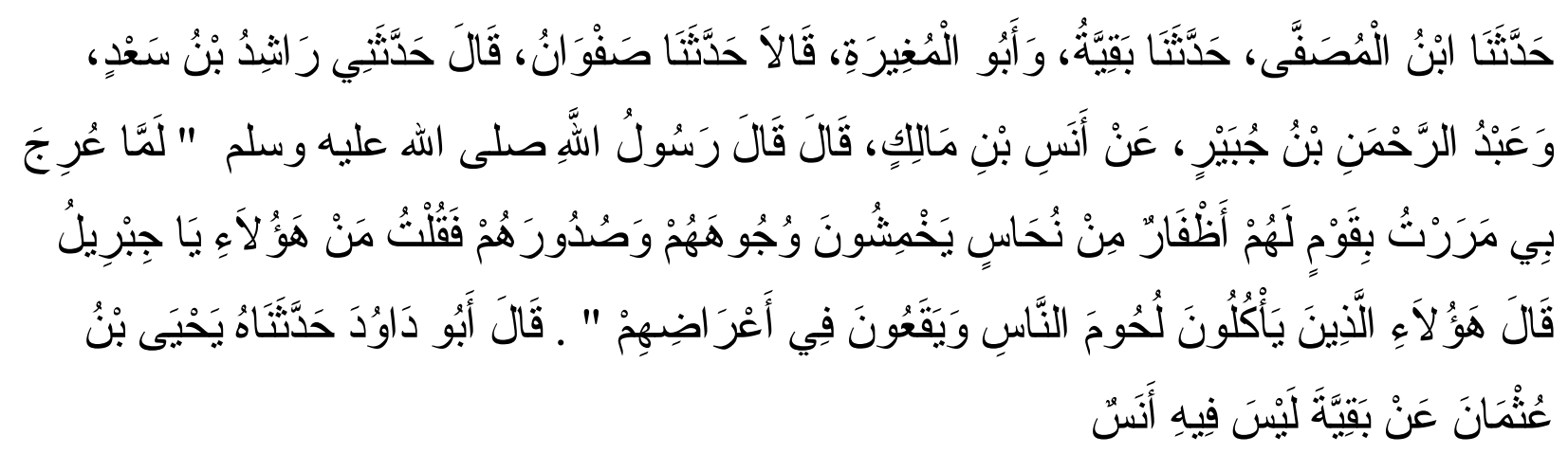

Artinya:

Telah menceritakan kepada kami Ibnu al-Mushaffa berkata, telah menceritakan kepada kami Baqiyyah dan Abu al-Mughirah keduanya berkata: telah menceritakan kepada kami Shafwan ia berkata; telah menceritakan kepadaku Rasyid bin Sa"d dan „Abdurrahman bin Jubair dari Anas bin Malik ia berkata, "Rasulullah SAW bersabda: "Ketika aku dinaikkan ke langit (dimi'rajkan), aku melewati suatu kaum yang kuku mereka terbuat dari tembaga, kuku itu mereka gunakan untuk mencakar muka dan dada mereka. Aku lalu bertanya, "Wahai Jibril, siapa mereka

${ }^{15}$ Wahid Abdus Salam, 40 Dosa Lisan Perusak Iman (Solo: Al-Qowan, 2005), hal. 64. 
itu?"Jibril menjawab, “Mereka itu adalah orang-orang yang memakan daging manusia (gibah) dan merusak kehormatan mereka.” (HR.Abu Daud 4235).

Melalui dua hadis diatas, gibah digambarkan sebagai perbuatan buruk yang harus dihindari. Pada hadis yang diriwayatkan Imam Ahmad dikatakan bahwa pembebasan dari neraka bagi orang yang menahan atau menahan gibah, sedangkan pada hadis yang diriwayatkan oleh Abu Daud berisi tentang siksaan dan perumpamaan bagi orang yang melakukan gibah dengan mencakar muka dan dada menggunakan kuku yang terbuat dari tembaga.

hadis yang berbicara tentang gibah lahir dalam konteks yang melarang perbuatan tersebut. Hal ini merupakan sebuah kewajaran lantaran gibah diartikan sebagai perbincangan tentang keburukan seseorang tidak secara langsung kepadanya. Akan tetapi, tidak semua aspek gibah merupakan hal yang terlarang karena terdapat beberapa sisi pembolehan terhadap gibah. Sebagai contoh, jika semua gibah merupakan terlarang, tentu tidak akan pernah dijumpai proses peradilan kasus KDRT karena pihak pelapor tentu akan membicarakan tentang keburukankeburukan pelaku. ${ }^{16}$

\section{Macam-Macam Ghibah Yang Dibolehkan}

Imam Nawawi dalam Riyadhu As-Shalihin menyatakan bahwa ghibah adalah perbuatan yang dilarang, kecuali diperbolehkan untuk tujuan syara yang tidak mungkin tercapai kecuali dengan ghibah. ${ }^{17}$

1. Ghibah untuk mengadukan kezhaliman (at-tazhallum)

Bagi orang yang dizhalimi boleh mengadukan kezhaliman kepada penguasa atau hakim, atau selain keduanya yang berkompeten untuk menghilangkan kezhaliman.Dan hal seperti itu dibolehkan, dalam Al-Qur'an Allah Swt berfirman pada surah An-Nisa:148:

\footnotetext{
${ }^{16}$ Ibnu Manzhur, Lisan Al-„Arab (Beirut: Dar al-Kutub al-Ilmiyah, 2009), 656.

${ }^{17}$ Musthofa Sa'id Al Khin, Nuzhatul Muttaqin Syarah Riyadhus Sholihin (Beirut: Mueassisah Ar- Risalah, 1987), hal. 134.
} 


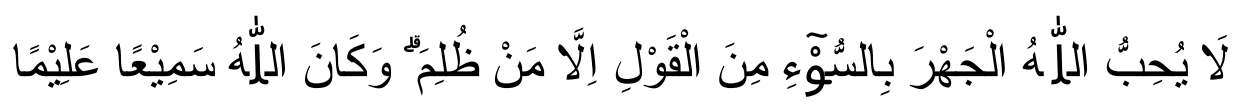

Artinya:

Allah tidak menyukai perkataan buruk, (yang diucapkan) secara terus terang kecuali oleh orang yang dizalimi. Dan Allah Maha Mendengar, Maha Mengetahui. ${ }^{18}$

2. Ghibah untuk meminta tolong (al-isti'anah)

Meminta bantuan untuk merubah kemungkaran dan mengembalikan orang yang maksiat menjadi taat kepada Allah Swt, kepada orang yang dirasa mampu untuk melakukannya.

3. Ghibah untuk meminta fatwa (istifta')

Seperti seseorang yang meminta fatwa kepada ulama dan ustadz, misalnya saudaraku menzhalimiku seperti ini, maka bagaimana hukumnya bagi diriku maupun saudaraku tersebut. Dalam sebuah Hadis dikisahkan bahwa Hindun binti Utbah (istri Abu Sufyan) meminta fatwa pada Rasulullah Saw, tentang suaminya:

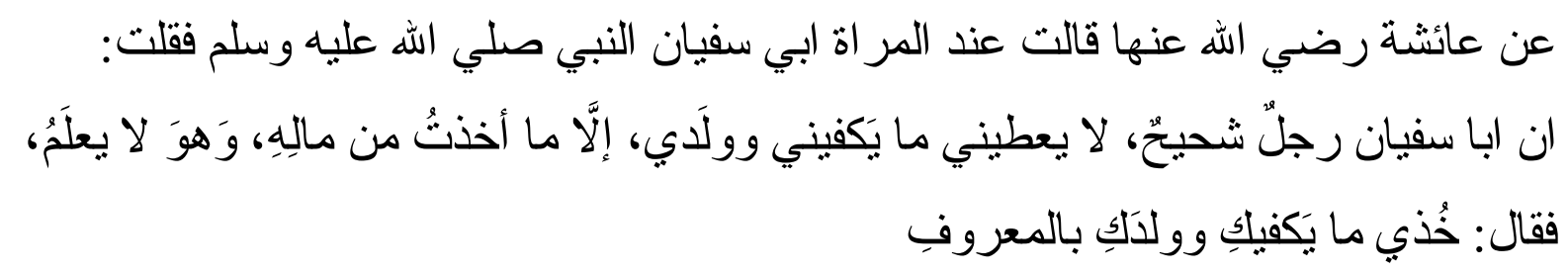

Artinya:

Dari Aisyah ra, dia berkata, Hindun istri Abu Sufyan berkata kepada Nabi Saw, Sesungguhnya Sufyan adalah seseorang laki-laki yang bakhil, dia tidak memberiku apa yang mencukupi kebutuhanku dan kebutuhan anakku, kecuali aku mengambil arinya sedang dia tidak tahu. Rasulullah Saw, bersabda, Ambillah apa-apa yang mencukupimu danh mencukupi anakku dengan maruf. ${ }^{19}$

\section{Dampak Perbuatan Ghibah}

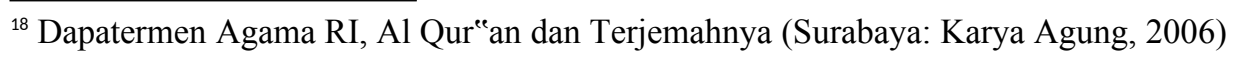

${ }^{19}$ Muslim, Shahih Muslim (Beirut: Dar-al Kitab „Araby, 2004), hal. 128. 
Manusia sebagai makhluk sosial, di saat berinteraksi terkadang disadari atau tanpa disadari ketika berkumpul perkataan yang diucapkan adalah penyakit lisan, yang dapat dikategorikan ghibah. $^{20}$

Ghibah merupakan penyakit berbahaya dan menimbulkan kemudharatan yang lebih besar di dunia maupun di akhirat kelak. Dan dampak negative yang ditumbulkan oleh ghibah, dalam bermasyarakat diantaranya: ${ }^{21}$

1. Timbulnya permusuhan.

Ghibah dapat menimbulakan permusuhan, jika orang yang di ghibahmengetahui dirinya menjadi objek ghibah, maka ia merasa tidak senang dengan orang yang yang telah berbuat ghibah pada dirinya.

\section{Terzhalimi}

Orang yang menjadi korban ghibah jika mereka mengetahuinya akan merasa terzhalimi, ia akan merasakan sakit tapi bukan tubuhnya yang terasa sakit, melainkan hatinya dan perasaannya.

\section{Merusak kehormatan orang lain}

Ghibah merupakan membuka aib seseorang yang secara otomatis telah menghinanya, dan akan mencemarkan nama baiknya. Maka Allah Swt juga akan membuka aib bagi siapa saja yang telah berbuat ghibah.

4. Memecah ukhuwah Islamiyah

Ghibah dapat menimbulakan perpecahan di masyarakat yang merusak ukhuwah Islamiyah. Dalam Al-Qur"an dijelaskan agar persatuan dan ukhuwah Islamiyah dijaga dengan baik. Allah Swt berfirman dalam surah Ali Imran ayat 103:

\footnotetext{
${ }^{20}$ Maulana Muhammad Yusuf, Muntakhab Ahadis, Dalil-Dalil Enam Sifat Utama (Yogyakarta: Ash Shaff, 2007), hal. 672 .

${ }^{21}$ Wahid Abdus Salam, 40 Dosa Lisan Perusak Iman (Solo: Al-Qowan, 2005), hal. 64. 


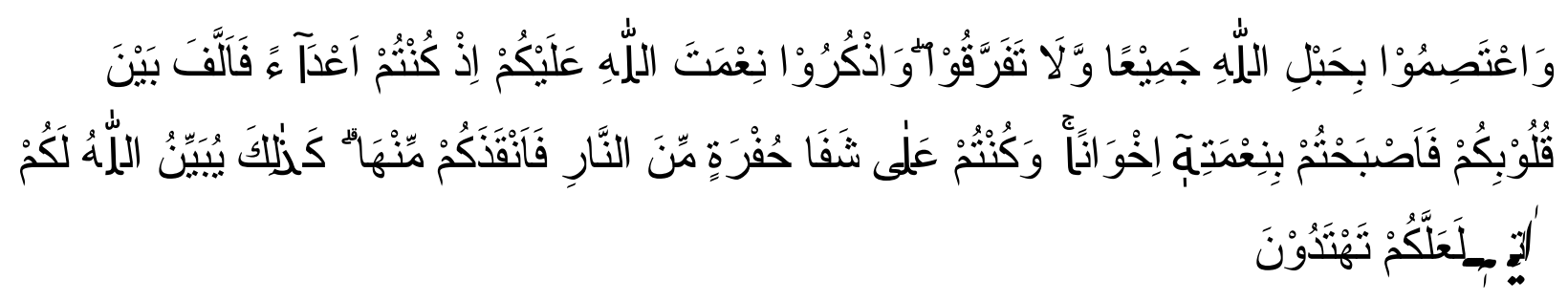

Artinya:

Dan berpegang teguhlah kamu semuanya pada tali (agama) Allah, dan janganlah kamu bercerai-berai, dan ingatlah nikmat Allah kepadamu ketika kamu dahulu (masa Jahiliah) bermusuhan, lalu Allah mempersatukan hatimu, sehingga dengan karunia-Nya kamu menjadi bersaudara, sedangkan (ketika itu) kamu berada di tepi jurang neraka, lalu Allah menyelamatkan kamu dari sana. Demikianlah, Allah menerangkan ayat-ayat-Nya kepadamu agar kamu mendapat petunjuk. $^{22}$

\section{Cara Mengobati Ghibah}

cara mengobati penyakit ghibah ialah menyadarkan orang yang mengghibah bahwa perbuatannya itu memancing kemurkaan Allah, kebaikan-kebaikanya akan berpindah pada orang yang di ghibah dan jika ia tidak mempunyai kebaikan, maka keburukan orang yang di ghibah akan dipindahkan kepada dirinya. Jika terlintas pikian untui mengghibah, maka hendaklah ia intropeksi diri dengan melihat aib diri sendiri lalu berusaha untuk memperbaikinya. Mestinya dia merasa malu jika mengungkap aib orang lain, sementara dirinya sendiri penuh dengan aib. Jika dia tidak mempunyai aib, yang lebih baik baginya adalah mensukuri nikmat Allah yang dilimpahkan kepadanya. Dan tidak perlu mengotori diri sendiri dengan aib yang sangat buruk, yaitu ghibah. Jika dia tidak ridha di ghibah oleh orang lain. Mestinya dia juga tidak berbuat ghibah untuk orang lain. Hendaklah seseorang melihat sebab yang mendorongnya untuk melakukan ghibah. Lalu hendaklah berusaha memotong sebab tersebut. Karena utuk mengobati suatu penyakit ialah dengan cara memotong penyebabnya. ${ }^{23}$

\footnotetext{
${ }^{22}$ Dapatermen Agama RI, Al Qur'an dan Terjemahnya (Surabaya: Karya Agung, 2006)

${ }^{23}$ Ibnu Qudamah, Mukhtasar Minhajul Qashidin (Beirut: Darul Fikr, 1989), hal. 212. 


\section{Kesimpulan}

Ghibah yaitu menyebutkan sesuatu yang sebenarnya tentang seseorang, baik tentang agamanya, akhlaknya, ataupun tentang yang lain, di saat orang tersebut tidak hadir atau tidak mendengarkan secara langsung, dan jika ia mengetahui tidak menyukainya.

menggunjing adalah haram baik dilakukan secara sadar atau tidak. Namun, ada beberapa pengecualian dengan diperbolehkannya gibah melalui pertimbangan syarat tertentu, yakni: Orang yang terzalimi Meminta pertolongan: Meminta fatwa dan nasihat; Memperingatkan orang-orang Islam dari perbuatan buruk: Menyebutkan tentang orang yang menampakkan kefasikan dan perilaku maksiatnya: serta Memberi julukan tertentu pada seseorang supaya lebih mengenalnya. Dalam konteks kehidupan masa kini, gosip boleh dilakukan selama memenuhi unsur-unsur yang diperbolehkan tersebut. Sebaliknya, jika gosip ini dilakukan diluar ketentuan tersebut, perilaku gosip ini hanya akan menimbulkan dampak yang negatif. Dampak negatif tidak hanya terhadap 
orang lain, melainkan juga dirinya sendiri. Secara luas, gosip akan menimbulkan permusuhan, konflik, dan pencemaran nama baik. Sementara, bagi seseorang yang sering bergosip, hal ini berpotensiberdampak pada kesehatan mental yang dapat memuncak sampai tingkat stress dan gangguan jiwa.

\section{Daftar Pustaka}

WJS Poerwadarminta, Kamus Umum Bahasa Indonesia Jakarta: PN. Balai Pustaka, 1985

Ahmad Warson Munawir, Al-Munawir: Kamus Arab-Indonesia Jakarta: Pustaka Progresif, 1984

Badudu and Sutan Mohammad Zain, Kamus Umum Bahasa Indonesia Jakarta: Pustaka Sinar Harapan, 1994

Ilyas, Ghibah Perspektif Sunnah,

Fatwa Majelis Ulama Indonesia Nomor 24 Tahun 2017, Komisi Fatwa Majelis Ulama Indonesia,

Muhammad Munzir, Gosip Dalam Pandangan Hadis: Suatu Kajian Tematik Fakultas Ushuluddin UIN Alauddin, 2011

Muslim, Shahih Muslim Beirut: Dar-al Kitab Araby, 2004

Yusuf Al Qardhawi, Al Halal Wa al Haram Fi al Islam Kairo: Maktabah Wahbah, 1993

Muslim, Shahih Muslim (Beirut: Dar-al Kitab Araby, 2004

Dapatermen Agama RI, Al Qur'an dan Terjemahnya Surabaya: Karya Agung, 2006

Jalaluddin Al-Mahalli, Jalaluddin Al-Mahalli, Tafsir Jalalain (Bandung: Sinar Baru 1990), (Bandung: Sinar Baru 1990),

Maulana Muhammad Yusuf, Muntakhab Ahadis, Dalil-Dalil Enam Sifat Utama Yogyakarta: Ash Shaff, 2007 
Muhammad bin Shalih al utsaimin, Hadis Arba'in Nawawiyah Yogyakarta: Absolut, 2005

Abdullah bin Jarullah, Awas Bahaya Lidah Jakarta: Gema Isnani Press, 1993.

Wahid Abdus Salam, 40 Dosa Lisan Perusak Iman Solo: Al-Qowan, 2005

Ibnu Manzhur, Lisan Al-Arab Beirut: Dar al-Kutub al-Ilmiyah, 2009

Musthofa Sa'id Al Khin, Nuzhatul Muttaqin Syarah Riyadhus Sholihin Beirut: Mu'assisah ArRisalah, 1987.

Muslim, Shahih Muslim Beirut: Dar-al Kitab Araby, 2004

Ibnu Qudamah, Mukhtasar Minhajul Qashidin Beirut: Darul Fikr, 1989 